IZA DP No. 9749

Evaluating the Long-Run Impact of an Innovative Anti-Poverty Program:

Evidence Using Household Panel Data

M Niaz Asadullah

Jinnat Ara

February 2016 


\title{
Evaluating the Long-Run Impact of an Innovative Anti-Poverty Program: Evidence Using Household Panel Data
}

\author{
M Niaz Asadullah \\ University of Malaya, University of Reading, \\ University of Oxford and IZA \\ Jinnat Ara \\ Bangladesh Rural Advancement Committee
}

Discussion Paper No. 9749

February 2016

\author{
IZA \\ P.O. Box 7240 \\ 53072 Bonn \\ Germany \\ Phone: +49-228-3894-0 \\ Fax: +49-228-3894-180 \\ E-mail: iza@iza.org
}

Any opinions expressed here are those of the author(s) and not those of IZA. Research published in this series may include views on policy, but the institute itself takes no institutional policy positions. The IZA research network is committed to the IZA Guiding Principles of Research Integrity.

The Institute for the Study of Labor (IZA) in Bonn is a local and virtual international research center and a place of communication between science, politics and business. IZA is an independent nonprofit organization supported by Deutsche Post Foundation. The center is associated with the University of Bonn and offers a stimulating research environment through its international network, workshops and conferences, data service, project support, research visits and doctoral program. IZA engages in (i) original and internationally competitive research in all fields of labor economics, (ii) development of policy concepts, and (iii) dissemination of research results and concepts to the interested public.

IZA Discussion Papers often represent preliminary work and are circulated to encourage discussion. Citation of such a paper should account for its provisional character. A revised version may be available directly from the author. 


\title{
ABSTRACT \\ Evaluating the Long-Run Impact of an Innovative Anti-Poverty Program: Evidence Using Household Panel Data*
}

\begin{abstract}
Using a four-round panel data set from the first phase of the Challenging the Frontiers of Poverty Reduction - Targeting the Ultra Poor (CFPR - TUP) programme of BRAC, we investigate whether a one-off transfer of livestock assets improves well-being of the very poor women in Bangladesh. Programme impact is assessed on a wide range of monetary and nonmonetary measures of wellbeing using difference-in-difference (DD) as well as matching methods. We find significant positive long-term impact on food security, household savings, assets and participation in microfinance. Participant women are less likely to be in distress occupation and more into self-employment. However, the long-term effect is much smaller for most outcomes when compared to short- and medium-run impacts. We conclude by discussing the significance of the institutional and regional context for the observed time path of estimated programme effect.
\end{abstract}

JEL Classification: $\quad$ O12, I30, D50

Keywords: Bangladesh, farm employment, food security, occupational choice, extreme poverty

Corresponding author:

M Niaz Asadullah

Faculty of Economics and Administration

University of Malaya

Kuala Lumpur 50603

Malaysia

E-mail:m.niaz@um.edu.my

\footnotetext{
${ }^{*}$ We gratefully acknowledge support from the Research and Evaluation Division (RED) of BRAC and would like to thank Mahabub Hossain, Narayan Chandra Das, Peter Davis and Simeen Mahmud for their helpful comments on an earlier version of the paper. We also thank seminar participants at BAPPENAS (Indonesian Ministry of National Development Planning) for useful suggestions. The usual disclaimers apply.
} 


\section{Introduction}

Bangladesh has made significant progress in rural poverty reduction over the past years. Yet one-fifth of its rural population lives in extreme poverty (World Bank, 2013). The ultra-poor households share multiple socio-economic characteristics such as being without any agricultural/homestead land, headed by a widow/female, having disabled adult male members, having no regular income source and remain excluded from NGO-run micro credit schemes (Halder and Mosley, 2004; Ahmed et al. 2007; Banerjee and Duflo, 2011; Davis, 2011). Acknowledging the association between gender and extreme poverty, the lack of productive assets and skills, and limits of conventional poverty schemes, BRAC, one of the world's largest NGOs, designed a program known as "Challenging the Frontiers of Poverty Reduction-Targeting the Ultra Poor" (CFPR-TUP) program, to reach the poorest of the poor and elevate them out of extreme poverty. The program includes direct transfers of income generating livestock assets and livelihood training and has reached thousands of female beneficiaries in Bangladesh. In addition to expanding coverage in Bangladesh, the TUP program has inspired similar initiatives in eight countries under the CGAP-Ford Foundation Graduation program (Hashemi and Montesquiou, 2011).

Existing research using non-experimental data confirms significant program impact on household income and food security most of which was also sustained after six years (Ahmed, Rabbani, Sulaiman, and Das, 2009; Krishna, Poghosyan and Das, 2012; Emran, Robano, and Smith, 2014). ${ }^{1}$ Evaluation using experimental data from Ethiopia, Ghana, Honduras, India, Pakistan, and Peru confirms sizable impact of the graduation model on the livelihoods of program participants (Banerjee, Duflo, Chattopadhyay and Shapiro, 2011; Banerjee, Duflo, Goldberg, Karlan, Osei, Pariente, Shapiro, Thuysbaret, and Urdy, 2015). Randomized evaluation of phase 2 of TUP scheme in Bangladesh yields similar results (Bandiera et al., 2013). However, evidence suggests a bigger program impact in some countries (e.g. Pakistan and West Bengal) than others (e.g. Honduras). Moreover, even a short-run impact is absent in one instance (Bauchet, Morduch and Ravi, 2015). Lastly, there is currently no evidence on the long-term benefits of participation in such programs owing to non-availability of suitable data.

\footnotetext{
${ }^{1}$ These studies evaluated program impact using two (2002 and 2005) or three rounds (2002, 2005 and 2008) of phase 1 data.
} 
The timing of impact evaluation is important because household and individual-level impacts are likely to vary over time (King and Behrman, 2009; Quisumbing, Baulch and Kumar, 2011). It may take time for households to realize the full return to their investments in projects involving assets received from the CFPR-TUP scheme. Female entrepreneurs may take longer to set up new enterprises and expand their business by securing access to additional financial resources. Successful transition to larger microenterprises in a patriarchal society hinges upon mobility into the male dominated public sphere as well as support from male household members. The institutional context in which the program is assumed to operate may also change over time (Bauchet, Morduch and Ravi, 2015). For these reasons, this paper revisits the evidence on phase 1 of CFPR-TUP using a four-round panel dataset that tracks treatment (selected ultrapoor) and control (non-selected ultra-poor) households in north-western Bangladesh over a period of 9 years (i.e. 2002 and 2011) in a quasi-experimental setting.

Consistent with previous assessment of medium-term effects, we present evidence on long-term effects in terms of changes in food expenditure, household assets, food security and microfinance participation. In addition to difference-in-difference method, matching methods are used to control for the differences between treatment and control households. However, for most outcomes including female selfemployment, program impact increases in the medium run but declines in the long-run. We conclude by highlighting the role of contextual factors specific to north-western region of Bangladesh that may influence the time-path of program effect after assistance was withdrawn.

The rest of the paper is organized as follows. Section 2 discusses BRAC's TUP program and set out the conceptual framework. We explain the selection criteria of program participants and the intervention package. Section 3 describes the sample and presents the descriptive statistics of the key variables included in the analysis. The empirical strategy is also discussed in this section. The results are presented in Section 4. We conclude in Section 5. 


\section{Program description and conceptual framework}

\subsection{Asset transfers vs. other approaches to poverty reduction}

The government of Bangladesh has implemented a number of interventions to help households move out of poverty. These have ranged from providing access to credit, skills training, safety net interventions, new technology to transfers of productive assets (Khandker, 2005; Quisumbing, Baulch and Kumar, 2011). These programs vary in terms of design (e.g. single vs. multi-components; conditional vs. unconditional transfer), targeting criteria (e.g. gender focused, individual vs. group based approach) and coverage of the poorest of the poor (Ahmed et al. 2007). ${ }^{2}$ Currently as many as 27 public safety net interventions operate to assist the poor in Bangladesh through transfers (World Bank 2013). Examples of existing short-term interventions are Food for Work and Cash for Work. Long-term schemes that offer both cash and food support throughout the year include the Employment Generation Program for the Poorest (EGPP), Vulnerable Group Development (VGD) and Vulnerable Group Feeding (VGF). Among these programs, EGPP is one of the largest public safety net programs in Bangladesh. However, some of these transfer interventions often fails to reach the very poor and do not by themselves trigger sustainable income growth for the poorest of the poor.

Because of the low level of physical capital endowment, the ultra-poor are often trapped in various forms of chronic deprivation. They need a critical push to uplift their initial endowment base, in as risk-free a manner as possible, to a certain level which is necessary for getting greater access to other resources and their productive utilization. In this setting, a one off asset transfers could be a valuable anti-poverty tool and serve as a powerful alternative to other poverty approaches such as cash and food transfer programs, microfinance or access to technology. However, the ultra-poor, particularly women, also lacks in human capital to excel in running small enterprises. So transfer of physical capital per se may not be sufficient to escape poverty trap.

\footnotetext{
${ }^{2}$ For instance, MFIs prefer moderately poor clients and non-agricultural portfolio (Sengupta and Aubuchon, 2008).
} 
By targeting females who are untrained and too poor to benefit from conventional poverty programs, schemes such as the TUP program serves to expand the available policy tools to reach out women in poverty. This approach might be better than conventional poverty reduction strategies for a number of reasons. First, poverty programs such as food-for-work primarily rely on the capacity to exchange labor and are not effective in helping the poor to escape poverty traps (e.g. under-nutrition related). Other safety net programs involving in-kind transfer are not sustainable as they do not help find regular income sources. Second, existing government safe net programs suffer from targeting error which is minimized in case of schemes run by established NGOs like BRAC. Third, provision of livelihood training ensures that assets transferred are not managed inefficiently because of lack of skills. In sum, through a creative combination of assets and skills training, the program enables female-headed households and other vulnerable families to 'graduate' out of extreme poverty by overcoming capital and skills constraints (Bandiera et al 2013). Close monitoring by NGO workers and intensive skills training facilitates 'graduation' from low-return livelihood strategy relying on agricultural wage labor to managing basic micro enterprises. In the next section, we describe the TUP program in detail.

\subsection{Program description}

The TUP program is built on two decades of experience of the World Food Program and the Government of Bangladesh sponsored scheme to assist vulnerable families to address food security through raising poultry and food aid. The scheme, Income Generation for Vulnerable Group Development (IGVGD), was launched in 1986 where an integrated package of food aid was provided to the extreme poor in Bangladesh along with provisions for savings, micro-credit and skill development training. Evaluation of this intervention showed that the impact was not sustainable (Hashemi, 2001; Matin and Hulme, 2003). Questions were raised about targeting effectiveness as many participating households were found to have not fulfilled all the eligibility criteria. BRAC responded by drawing up the CFPR-TUP program which was initially introduced in 2002 in three of the poorest districts of Bangladesh, Rangpur, Kurigram and Nilphamari. Later on it extended to another 12 districts. 
The TUP scheme roughly targets the bottom 10 percent population in the income distribution. Compared to IGVGD, the scheme first identifies the extreme poor using a community based participatory wealth ranking method. Usually households in the poorest category of wealth rankings were considered as the 'ultra-poor' though sometimes households in the poorest two categories were also considered. Among the ultra-poor, a group of households were selected to receive program support based on the inclusion and exclusion criteria. To be eligible, an ultra-poor women must meet at least three of the following five criteria: (a) the household is dependent upon female domestic/seasonal work for example, begging, maid (b) own less than 10 decimals of land (c) no active male adult member in the household (d) no productive assets in the household (e) children of school going age have to take paid work. In addition, there are three exclusion criteria are: (a) no adult woman in the household who is able to work; (b) participating in microfinance; and (c) beneficiary of government/NGO development project. Any ultra-poor household meeting at least three of the inclusion and none of the exclusion criteria is selected to receive benefits from program. An additional round of verification is carried out by BRAC to generate the final list of households eligible for CFPR-TUP support. Those who received program benefit are called SUP (selected ultra-poor) households.

Once female beneficiaries are selected, BRAC helps them to identify appropriate income generating micro-enterprises through extensive consultation with respective household members. After finalization of enterprise choice, beneficiaries participate in orientation training on the program and the enterprise. The multi-component TUP program then begins by a transfer of productive assets worth taka 10,000 to support development of the selected enterprise. Over $90 \%$ of SUP households chose a livestock combination (e.g. cow, goat, poultry etc); only a handful of beneficiaries opted for vegetable-nursery growing or non-farm enterprises. The asset is usually transferred within one month of the orientation training (Ahmed et al., 2009).

In addition, program participants are encouraged to save in TUP fund immediately after joining the program. Other supplementary program components included monthly visits by health workers, weekly 
follow-up session to provide technical advice, build social awareness, and a weekly stipend of taka $70 .^{3}$ In case of loss of transferred assets due to unforeseen shocks, a second round support is provided. The intervention therefore combines support for immediate consumption needs with longer term investments in training and business development so that after two years ultra-poor people are equipped to help themselves "graduate" out of extreme poverty. ${ }^{4}$

\subsection{Understanding program impact over time}

Considering a longer assessment window is important because the time-path of impact varies across interventions. The implementation cycle differs from project to project leading to variation in the duration of exposure to a treatment across program areas and beneficiaries. Owing to length of the implementation cycle and nature of outcome variables, the timing of evaluations matters (King and Behrman, 2009). Depending on the time path of impact, an early evaluation risks under/over-estimating the impact. In case of TUP phase-1, the program implementation cycle was 24 months. Soon after the intervention, it is natural to see a jump in livestock asset holding and associated earnings. However, households have to wait before they can trade them to acquire bigger assets and/or diversify the asset portfolio. Only having established and run a successful livestock/poultry based business for a few years, the household can 'trade-in' the stock to buy a larger and more indivisible income earning asset, such a cow, a rickshaw or a small shop. For this reason, we expect the return to increase further after 4-6 years of the intervention. At the same time, absence of male working and extended family members can limit access to additional social support in running the household's new economic enterprise (Hashemi and Montesquiou, 2011). In patriarchal settings, women's socio-cultural barriers and other specific obstacles like access to the market and short-term loans prevent her from expanding her business. In sum, whilst initial transfers of asset can succeed in putting females in

\footnotetext{
${ }^{3}$ The provision of stipend money helps protect against distress selling of assets to fight short-term food insecurity and hunger and in general continues up to $8-10$ months.

${ }^{4}$ The progress made over the last decade has led BRAC to introduce the next phase of the program. The second phase started in 2007 covering 40 districts and 300,000 beneficiaries (Das and Shams, 2011).
} 
poultry and livestock management, whether they build on this and continue to run micro-enterprises long after the intervention can only be assessed through long-term evaluation.

Lastly, external factors beyond the program's reach can significantly influence its outcomes. Rangpur region is characterized by many conditions (e.g. absence of local markets to sell produces from small enterprises, lack of physical infrastructure and adverse agro-climatic factors) that potentially limits basic entrepreneurial activities including up-gradation of micro enterprises in the long-run. Moreover, the relative return to livestock and poultry rearing vis-a-vis agricultural wage work may change over time. Since the TUP program works by moving females out of agricultural wage work, participant households are less likely to be affected by labor market shocks. But shocks (e.g. food price rise) that increase demand for agricultural labor can benefit control households relying on agriculture. In addition, program impact depends on the availability of close substitutes to the program (Bauchet, Morduch and Ravi, 2015). The larger institutional context and how it may have changed over time is therefore critical to understanding program effect over time. When discussing the main results in section 4, we elaborate on these issues.

\section{Data and empirical methods}

\subsection{Data}

Our evaluation focuses on changes in outcomes in the treatment and control groups following the introduction of the CFPR-TUP scheme between 2002 and 2011. The baseline survey was carried out during June-August, 2002 in Rangpur, Kurigram and Nilphamari districts. The sample size was 5,626 households (of which 2,633 were treatment households). In follow up surveys carried out in 2005 and 2008, a total of 5,228 and 4,559 households were tracked respectively. The fourth round survey, conducted in 2011, traced 4038 households. In other words, a total of 1588 households were lost between 2002 and 2011. Compared to non-attrition households, attrition households have significantly less cash savings, live in poor household conditions, are less food secure, have fewer assets and more likely to be female headed. Whether these differences would lead to a downward bias in the impact analysis of TUP depends on the way in which sample attrition affected program and non-program households. To this end, Appendix Table 1 presents 
disaggregated attrition data separating out treatment and control households. Of the total households lost, $52 \%$ were treatment households. These households were poorer compared to control households in terms of cash savings, education level and asset ownership. In order to test whether sample attrition was excessively concentrated in treatment sample, we regressed attrition dummy on treatment dummy (controlling for village of location). Results indicate that the treatment dummy was never significant (Appendix Table 2).

\subsection{Empirical Strategy}

We have a quasi-experimental set up where data on treatment and control sample are available from pre- and post-intervention periods. In order to explore the correlations formally, we begin with difference-indifference (DD) technique which focuses on the difference between the treatment and control group from the pre-programme period to the follow-up period. The ordinary least square (OLS) regression function used to estimate DD impact using four rounds of panel data is as follows:

$\mathrm{Y}_{\mathrm{it}}=\alpha+\beta_{1} \mathrm{~T}_{2005}+\beta_{2} \mathrm{~T}_{2008}+\beta_{3} \mathrm{~T}_{2011}+\beta_{4} \mathrm{SUP}+\beta_{5} \mathrm{~T}_{2005} * \mathrm{SUP}+\beta_{6} \mathrm{~T}_{2008} * \mathrm{SUP}+\beta_{7} \mathrm{~T}_{2011} * \mathrm{SUP}+\mathrm{e}_{\mathrm{i}}$

where $Y_{i t}$ is outcome variable of interest for household (or individual) i at time $t ; T_{j}$ are time dummies $(j=2005,2008$ and 2011) and SUP is treatment household dummy. The constant term $(\alpha)$ is the mean value of the outcome variable for the control households in the baseline; $\beta_{1}, \beta_{2}$, and $\beta_{3}$ measures change in outcome variable from baseline to follow up survey $\left(2005,2008\right.$, and 2011) for control households; $\beta_{4}$ measures the difference in outcome variable between SUP and control households at the baseline; the key parameter of interest, $\beta_{5}, \beta_{6}$, and $\beta_{7}$, are our double difference estimators of the outcome variable (i.e. average treatment effect). In this setting, $\beta_{5}, \beta_{6}$, and $\beta_{7}$ correspond to the short- (2005 over 2002), medium(2008 over 2002) and long-run (2011 over 2002) measures of program impacts respectively.

Although the surveyed households were extreme poor and selected based on specific selection criteria, they were not similar in terms of their economic and demographic characteristics (see Appendix Table 3). Consequently the two groups of households may not have experienced the same growth trajectory overtime without the intervention. Therefore we also re-estimate equation (1) additionally controlling for 
selected baseline characteristics such as sex of the household head, occupation of the main female of the household, household members' literacy, economic status, and asset holding of the households. To further check the sensitivity of impact estimates, we use propensity score matching (PSM). The PSM method of program evaluation constructs a comparison group who are likely to be similar to the treated (i.e. have similar inclusion probability densities) contingent upon baseline participation by matching intervention sample to comparison group based on observable characteristics. ${ }^{5}$ The impact of the program is then estimated as the average difference in the outcomes for each intervention respondent from a weighted average of outcomes in each similar comparison group of respondent from the matched sample. We implement the PSM method in the following steps. First, a probit model using baseline (2002) data is estimated. Second, we check the balancing properties of the data by testing whether treatment and comparison groups have the same distribution (mean) of propensity scores and of variables within groupings of the propensity score. Variables not satisfying this are dropped or replaced with alternative variables and the specification is rechecked. Third, we estimate the matching equations using the common support restriction (to ensure that matches are formed only where the distribution of the density of the propensity scores overlap between treatment and control groups). Subsequently we match the propensity score between the treatment and control groups through the nearest neighbourhood matching technique using STATA's psmatch2 command (see Appendix Table 4 for regression results on the propensity scores).

\section{4. $\quad$ Results and Discussion}

In this section we look into the causal impact of TUP program (summary statistics by program participation status are presented in Appendix Table 3). Although we construct three sets of estimates - DD, DD with baseline characteristics control and DD matching, for the sake of brevity, we do not discuss the second set of estimates. It is because point estimates are very similar to unconditional DD figures. To understand whether

\footnotetext{
${ }^{5}$ The propensity score matching approach is valid under the assumption that the differences in participation are solely based on observed characteristics of baseline survey. However, it is possible that during the selection process, BRAC officials have favoured participants who are more motivated and ambitious but have lower ability. If so, treatment and control households are likely to differ with their unobservable characteristics. This remains an important caveat for our analysis.
} 
and how the program effect varies over time, we separately present estimate of the short-, medium- and long-term impact on a range of monetary and non-monetary indicators.

\subsection{Impact on household wealth, occupation, food security, income and microfinance uptake}

Table 1 presents evidence of impact on household assets. For most indicators (e.g. \# of cows, goats, bed, chair/table and rickshaw van), larger size of the medium term impact indicates that treatment households succeeded in expanding their asset base beyond what was provided by the program initially. However, DD as well as DD-PSM estimates indicate a declining program impact over 2002-2011 period. In some instances, the long-term effect is insignificant even at 10\% level (e.g. cultivable land holding size). This pattern remains unchanged when we re-examine the data by aggregating assets into farm and non-farm as well as transferred and non-transferred assets. Overall, there is no indication that households changed their portfolio by consolidating transferred agricultural assets to acquire more non-farm assets.

Table 1: Difference-in-difference (DD) and DD-PSM estimates of the impact of the TUP programme on household assets

\begin{tabular}{|c|c|c|c|c|c|c|}
\hline & \multicolumn{3}{|c|}{ DD } & \multicolumn{3}{|c|}{ DD-PSM } \\
\hline & $\mathrm{T}_{2005 * \mathrm{SUP}}$ & $\mathrm{T}_{2008 * \mathrm{SUP}}$ & $\mathrm{T}_{2011} * \mathrm{SUP}$ & $\mathrm{T}_{2005 * \mathrm{SUP}}$ & $\mathrm{T}_{2008 * \mathrm{SUP}}$ & $\mathrm{T}_{2011} * \mathrm{SUP}$ \\
\hline & (short-run & (medium-run & (long-run & (short-run & (medium-run & (long-run \\
\hline & impact, 2005- & impact, 2008- & impact, 2011- & impact, 2005- & impact, 2008- & impact, 2011- \\
\hline & 2002) & 2002) & 2002) & 2002) & 2002) & 2002) \\
\hline \multicolumn{7}{|c|}{ Natural and physical asset (individual index) } \\
\hline Homestead land owned (decimal) & $0.68 * * *$ & $0.96 * * *$ & $0.70 * * *$ & 0.01 & $0.29 *$ & 0.22 \\
\hline Cultivable land owned (decimal) & 0.60 & $1.09 * *$ & 0.58 & -0.40 & -0.02 & -0.33 \\
\hline No. of cow/bull owned & $1.58 * * *$ & $1.11 * * *$ & $0.61 * * *$ & $1.49 * * *$ & $1.03 * * *$ & $0.54 * * *$ \\
\hline No. of goat/sheep owned & $0.40 * * *$ & $0.38 * * *$ & $0.19 * * *$ & $0.37 * * *$ & $0.38 * * *$ & $0.18 * * *$ \\
\hline No. of duck/hen owned & $0.55 * * *$ & $1.96 * * *$ & $1.19 * * *$ & $0.50 * * *$ & $1.73 * * *$ & $0.81 * * *$ \\
\hline No. of rickshaw/van owned & $0.05 * * *$ & $0.06 * * *$ & $0.02 *$ & $0.04 * * *$ & $0.04 * * *$ & 0.00 \\
\hline No. of Trees owned & $0.65^{* *}$ & $0.62 * *$ & $0.76 * * *$ & $0.10 * * *$ & $0.18 * * *$ & $0.18 * * *$ \\
\hline No. of bed owned & $0.13 * * *$ & $0.21 * * *$ & $0.22 * * *$ & $0.11 * * *$ & $0.18 * * *$ & $0.10^{*}$ \\
\hline No. of chair/table owned & 0.07 & $0.13 * *$ & 0.04 & $0.34 *$ & $0.60 * * *$ & 0.12 \\
\hline \multicolumn{7}{|l|}{ Aggregate index } \\
\hline Aggregate business asset & $0.08 * * *$ & $0.08 * * *$ & $0.05 * * *$ & $0.08 * * *$ & $0.07 * * *$ & $0.05 * * *$ \\
\hline Aggregate non-business asset & $0.01 * * *$ & $0.02 * * *$ & $-0.02 * * *$ & $0.01 * * *$ & $0.02 * * *$ & $0.02 *$ \\
\hline Aggregate transferred asset & $0.08 * * *$ & $0.09 * * *$ & $0.05 * * *$ & $0.08 * * *$ & $0.08 * * *$ & $0.05 * * *$ \\
\hline Aggregate non-transferred asset & $0.01 * * *$ & $0.03 * * *$ & $0.02 * * *$ & $0.02 * * *$ & $0.02 * * *$ & $0.02 * *$ \\
\hline
\end{tabular}

Note: (a) Results are obtained from OLS estimation of equation 1. (b) Each set of short, medium and long-term estimates (corresponding to an outcome variable) relates to parameters $\beta_{5}, \beta_{6}$, and $\beta_{7}$ respectively in equation 1 . Other estimated parameters are not reported to save space. (c) DD-PSM estimates are obtained by applying DD technique to matched sample observations. (d) $* * *, * *$ and $*$ refer to $1 \%, 5 \%$ and $10 \%$ level of significance respectively. (e) Aggregate asset indices have been constructed following the principal-component analysis. 
Table 2: Difference-in-difference (DD) and DD-PSM estimates of the impact of the TUP programme on primary occupation of the working aged individuals (15-60 years)

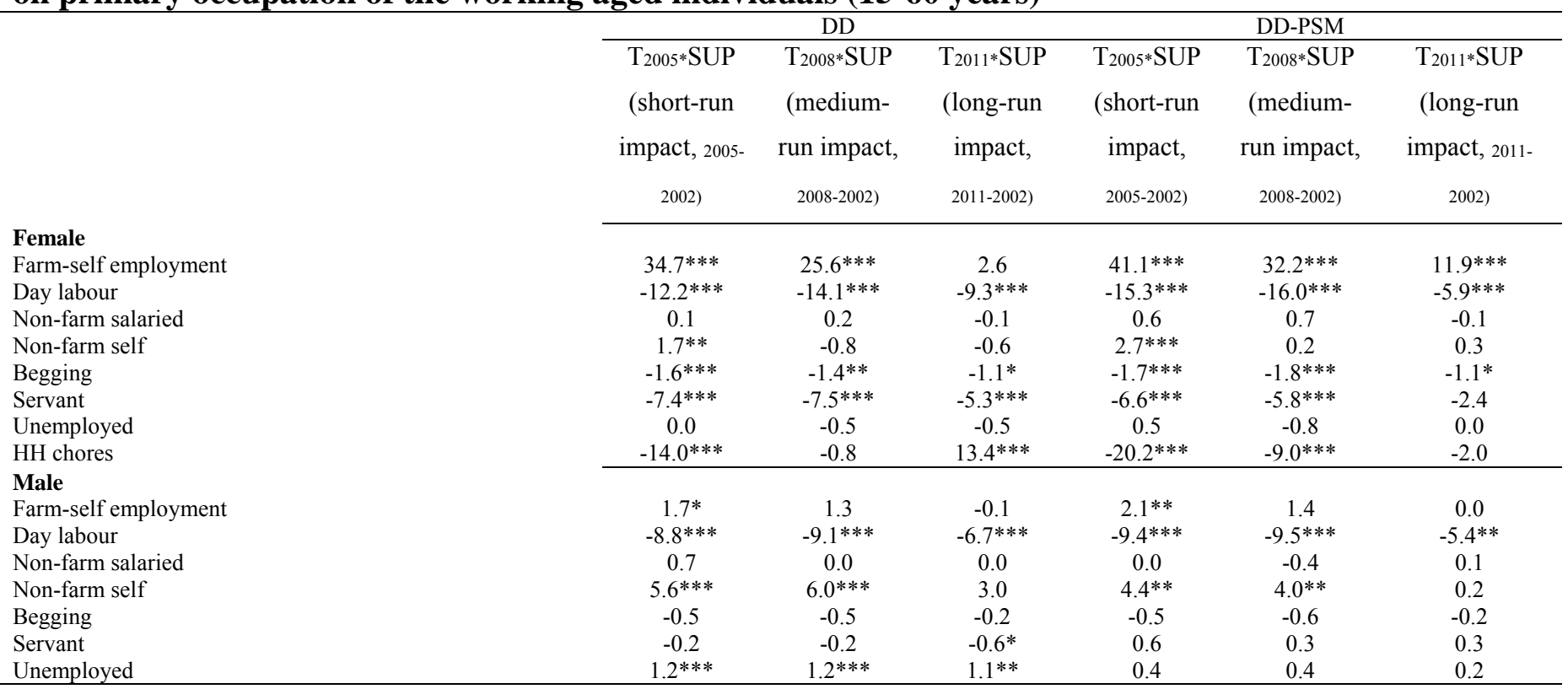

Note: see Table 1.

The increase in household assets reported in Table $\mathbf{1}$ is consistent with changes in household occupation reported in Table 2. Both DD and DD-PSM estimates show statistically significant program effect on agricultural self-employment in the short as well as medium-term. However, DD estimate of the long-term effect is statistically insignificant. The corresponding DD-PSM estimate is significant but smaller compared to short- and medium-term estimates. On the other hand, program impact on agricultural wage work is negative and significant. The evidence of declining program effect is also noticeable in case of day labor. Similarly, the large negative impact on distress employment (begging and working as servants) amongst program women was significantly attenuated by 2011.

Several hypotheses may explain the fall in female participation in self-employment and the rise in household chores. First, female members may have genuinely moved out of self-employment in the long-run and gone back into household chores. ${ }^{6}$ Enhanced asset base may have provided the much needed financial

\footnotetext{
${ }^{6}$ Women who have taken up livestock rearing work as part of the intervention could find it more convenient to hand over their enterprises (e.g. poultry rearing) to other household members or move on to activities that can be combined more easily with household work. Such dynamics surrounding management and control of economic resources are well-documented in case of micro-credit services. Studies have shown that in most cases men use NGO credit and husbands' income remain a key source of instalment payments (Goetz and Gupta, 1996; Hashemi, Schuler and Riley, 1996; Sengupta and Aubuchon, 2008). Evidence on occupational choice of female participants in microfinance also finds limited evidence of radical change in the gender division of
} 
platform for male members to set up new micro enterprises. Second, due to more intensive contact with BRAC staff in the early years influencing their views, or as livestock and poultry go through several generations, the link with the initial asset transfer to the female beneficiary could become weaker in female beneficiaries' minds leading to differences in reported primary occupation.

In order to better understand the above possibilities, we separately looked at occupational change amongst working-aged males. There is some evidence in support of the hypothesis that male members in SUP sample took over enterprise ownership allowing females to fall back into household chores. Males of the SUP households were significantly engaged in non-farm self-employment whilst their dependence on day laboring, begging and housemaid/servant had declined. Only short and medium-term DD and DD-PSM estimates are significant. On the other hand, farm self-employment increased among the working aged male members over the years though the impact is statistically insignificant throughout. Furthermore, we analyzed the primary occupation of the working aged female members whose households have an active male member with those where no active male member is present. Results show a higher percentage of females members were engaged in distress occupation like day laboring, begging as well as housemaids when no active male member is present. However, when no active male member was present in the baseline, female participation in self-employment remained significantly higher even in 2011. When formally examined using DD approach, the effect remains significant (results not reported but available from the authors upon request). In order to explore the second possibility, we examined secondary occupation of female members (data only available for 2011). The data indicates a large number of program women reporting household chores as the primary but self-employment as the secondary occupation. This implies that the reported longterm occupation pattern in the data could be still consistent with the story of a positive program impact on microenterprise development in intervention area.

Table 3 confirms positive and highly significant impact on program participants with regard to savings, outstanding loan and lending. DD and DD-PSM estimates of long-term effect are also significant in

labor resulting from women's access to credit. Women are still doing traditional home-based jobs like poultry raising, tailoring and paddy husking (Kabeer, 2001). 
case of cash savings and outstanding lending. The observed change in program impact on credit demand observed between 2002 and 2008 is consistent with growth in household assets and engagement in microenterprise activities during the period. ${ }^{7}$ However, as before, size of the estimated long-run effect is smaller when compared to short- and medium-term effects. ${ }^{8}$

Table 3: Difference-in-difference (DD) and DD-PSM estimates of the impact of the TUP programme on financial market participation

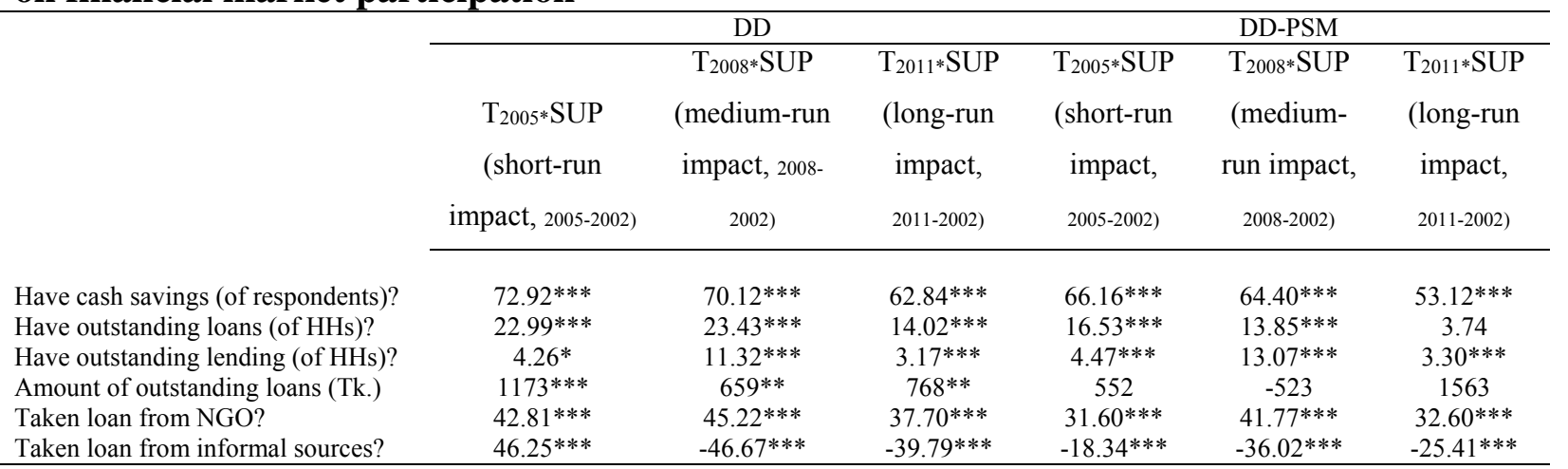

Note: The variable "Taken loan from NGO" is defined on the basis of response to question "Do you have any outstanding loan? If yes then mention sources of loan and name of the sources".

Table 4: Difference-in-difference (DD) and DD-PSM estimates of the impact of TUP programme on food security, food expenditure and income

\begin{tabular}{|c|c|c|c|c|c|c|}
\hline & \multicolumn{3}{|c|}{ DD } & \multicolumn{3}{|c|}{ DD-PSM } \\
\hline & $\begin{array}{l}\mathrm{T}_{2005 * \mathrm{SUP}} \\
\text { (short-run impact, } \\
\text { 2005-2002) }\end{array}$ & $\begin{array}{c}\mathrm{T}_{2008 * \mathrm{SUP}} \\
\text { (medium- } \\
\text { run impact, } \\
\text { 2008-2002) }\end{array}$ & $\begin{array}{c}\text { T2011*SUP } \\
\text { (long-run } \\
\text { impact, } \\
\text { 2011-2002) }\end{array}$ & $\begin{array}{c}\mathrm{T}_{2005 * \mathrm{SUP}} \\
\text { (short-run } \\
\text { impact, } \\
\text { 2005-2002) }\end{array}$ & $\begin{array}{c}\mathrm{T}_{2008 * \mathrm{SUP}} \\
\text { (medium- } \\
\text { run impact, } \\
\text { 2008-2002) }\end{array}$ & $\begin{array}{c}\mathrm{T}_{2011 * \mathrm{SUP}} \\
\text { (long-run } \\
\text { impact, } \\
\text { 2011-2002) }\end{array}$ \\
\hline $\begin{array}{l}\text { (a) Food Security } \\
\text { Always deficit } \\
\text { somewhat deficit } \\
\text { Neither deficit nor surplus } \\
\text { Surplus }\end{array}$ & $\begin{array}{l}-31.76 * * * \\
12.12 * * * \\
14.96 * * * \\
4.69 * * * \\
\end{array}$ & $\begin{array}{l}-25.63 * * * \\
11.93 * * * \\
10.50 * * * \\
3.20 * * * \\
\end{array}$ & $\begin{array}{c}-19.68 * * * \\
11.84 * * * \\
7.15 * * * \\
0.68 \\
\end{array}$ & $\begin{array}{c}-28.85 * * * \\
6.49 * * \\
17.42 * * * \\
4.95 * * * \\
\end{array}$ & $\begin{array}{c}-17.15^{* * *} \\
5.96^{* *} \\
9.10^{* * *} \\
2.09^{* * *} \\
\end{array}$ & $\begin{array}{c}-13.91 * * * \\
7.80 * * * \\
5.80 * * * \\
0.31 \\
\end{array}$ \\
\hline $\begin{array}{l}\text { (b) Per capita food expenditure and income } \\
\text { Per capita food expenditure (per day) } \\
\text { Per capita income (yearly) }\end{array}$ & $\begin{array}{c}- \\
969^{* * *} \\
\end{array}$ & $\begin{array}{l}3.52 * * * \\
1802 * * *\end{array}$ & $\begin{array}{c}1.52 * * * \\
-- \\
\end{array}$ & $\begin{array}{l}-- \\
--\end{array}$ & $\begin{array}{c}2.43 * * * \\
-- \\
\end{array}$ & $\begin{array}{c}0.48 * * \\
-- \\
\end{array}$ \\
\hline
\end{tabular}

Note: see Table 1.

Next we compare the program impact on household assets, occupational structure, and financial choices reported in Tables 1-3 with that on food security and household income (see Table 4). The DD estimates are always found to be negative and statistically significant at 1 level for the indicator variable "Always in deficit". The impact on extreme food insecurity declines over time with the long-term effect being much smaller. This is true irrespective of whether we use simple DD method or DD matching estimator. Per capita

\footnotetext{
${ }^{7}$ More than two-thirds of the CFPR-TUP graduates participated in BRAC microfinance (Shams, Mahmud and Das, 2010).

${ }^{8}$ An exception is DD and DD-PSM estimates on informal sources which indicate reduced dependence over time.
} 
food expenditure has increased for both groups in 2008 and 2011 but pronounced more among the SUP households which were highly significant. However, the long-run (2002-2008 and 2002-2011) impacts are positive and statistically significant at the level of 1 . When compared to double difference estimates, PSM estimates suggest smaller impact of both the medium and long-term effects. In addition, longer term effect remains smaller than the medium term effect. Because of absence of comparable data in 2011 round, we could not estimate the long-run impact on household income. However, estimates based on earlier rounds of data yields results that are consistent with estimates on program impact on food expenditure (Table 4).

In sum, the TUP scheme succeeded in transforming occupational structure and asset base of treatment households. However, the change was not sustained nice years after the transfer of productive asset. This finding contrasts with evidence on the short and medium term impact of the program documented for Bangladesh and other countries. ${ }^{9}$ This could be owing to changes in the factor market and other institutions some of which may have differentially affected treatment and control households in different time periods. We discuss this next.

\subsection{Contextualizing the results}

Given the fact that phase 1 of the TUP scheme started in 2002 and our sample comes from north-western Bangladesh, this section contextualizes the main findings taking into account the national and regional trends in poverty. The decline in poverty during 2000-2010 in Bangladesh is characterized by two underlying processes. During the first half of the decade, economic growth reduced poverty benefiting those who moved from agricultural labor to non-farm production. Poverty decline was larger amongst households with more landholding during 2000-2005. Increased wage returns to education also helped to reduce poverty but only in the non-agricultural sector.. During 2005-2010, redistributive public programs played a greater role in poverty reduction. This period saw larger fall in poverty to land-poor (i.e. the most deprived) households who relied on agricultural work. There was an increase in income earned by individuals with

\footnotetext{
${ }^{9}$ For instance, based on six randomized trials in Ethiopia, Ghana, Honduras, India, Pakistan, and Peru, Banerjee et al. (2015) found no evidence of decline in the impact of the program on consumption, household assets, and food security three years after the transfer of productive asset.
} 
lower levels of schooling. The exogenous increase in food price led to the increase in demand for unskilled workers along with a rise in agricultural wage rate in rural areas. Labor income increased despite a lack of change in labor productivity (Jacoby and Dasgupta 2012). Transfers from public safety net programs and private sources (e.g. remittance) grew during 2000-2010 suggesting that non-labor income also contributed to poverty decline. However, government schemes suffered from poor targeting thereby limiting their impact on poverty despite increased public spending.

In addition to the temporal differences described above, the pattern of poverty reduction varied across regions. Most of the daily workers and self-employed in agriculture are located in the western part of Bangladesh. Their low participation in non-agricultural work meant that during 2000-2005, the region saw small progress in poverty. However, the East-West divide in poverty disappeared during the second half of the decade as the western part benefited from higher wages in agriculture. In other words, poverty declined broadly across both the eastern and western divisions during 2005-2010. The only exception is the northwestern districts of Rangpur division where phase 1 of TUP scheme was implemented. Compared to other divisions, Rangpur has the highest prevalence of poverty (42\%) and extreme poverty (28\%) and lagged behind other regions even by 2010 (World Bank, 2013). Most poor workers in the region are still employed in the agricultural sector. ${ }^{10}$ At the same time, real wage rate and employment opportunities did not increase significantly despite rise in wage rates relative to other divisions (Khandker and Mahmud, 2011). All these factors leave households in the division vulnerable to seasonal hunger arising from agricultural seasonality. To cope with this, the extreme poor households often engage in employment diversification (switch from farm work to irregular non-farm work) during the lean season (usually September-November) thereby reducing the scope for achieving economies of scale in non-farm self-employment.

Lastly two institutional changes in greater Rangpur region during 2002-2010 are noteworthy for interpreting our results. First, a microfinance program known as PRIME was introduced in 2006 to address

\footnotetext{
${ }^{10}$ The share of farm work in total household income increased from $43.2 \%$ in 2000 to $55.9 \%$ in 2010 in Rangpur division (Khandker and Samad, 2012).
} 
seasonal as well as extreme poverty. ${ }^{11}$ Besides providing production-related loans, PRIME offered extension and training services. Evaluation of the program impact shows that PRIME is more effective than regular microfinance in reaching the ultra-poor and reducing extreme poverty (Khandker, Khalily and Samad, 2010). Second, government-run social safety-net programs expanded their coverage in the northwestern region which was found to have a positive effect on mitigating food deprivation (Khandker, Khaleque and Samad, 2010).

Table 5: Difference-in-difference (DD) and DD-PSM estimates of the impact of TUP programme on crisis and shocks

\begin{tabular}{|c|c|c|c|c|c|c|}
\hline & \multicolumn{3}{|c|}{ DD } & \multicolumn{3}{|c|}{ DD-PSM } \\
\hline & & $\mathrm{T}_{2008 * \mathrm{SUP}}$ & & & $\mathrm{T}_{2008 * \mathrm{SUP}}$ & $\mathrm{T}_{2011 * \mathrm{SUP}}$ \\
\hline & $\mathrm{T}_{2005 * \mathrm{SUP}}$ & (medium-run & (long-run & (short-run & (medium- & (long-run \\
\hline & (short-run & impact, 2008- & impact, & impact, & run impact, & impact, 2011- \\
\hline & impact, 2005-2002) & 2002) & 2011-2002) & 2005-2002) & 2008-2002) & 2002) \\
\hline \multicolumn{7}{|c|}{$\begin{array}{l}\text { (a) Crisis/Incidence occurred in last one year } \\
(\text { yes }=1 \text { ) }\end{array}$} \\
\hline House damaged & 1.94 & -2.28 & -2.75 & 3.57 & 1.53 & 0.96 \\
\hline HH members seriously ill & -0.42 & 1.26 & 0.34 & -1.72 & -0.78 & -0.70 \\
\hline Death of livestock & $7.24 * * *$ & $4.79 * * *$ & $15.99 * * *$ & $7.13 * * *$ & $4.55 * * *$ & $17.03 * * *$ \\
\hline Death of duck/hen & $-1.33 * *$ & $8.30 * * *$ & 1.56 & 1.85 & $9.85 * * *$ & 0.59 \\
\hline Loss by thief/robbery & 0.08 & 0.06 & $-0.75^{*}$ & 0.10 & -0.01 & -0.47 \\
\hline \multicolumn{7}{|c|}{ (b) Money spent for the incidence (yes=1) } \\
\hline House damaged & -4.06 & 0.17 & 0.33 & 1.75 & 1.45 & 0.79 \\
\hline HH members seriously ill & 0.14 & 0.42 & 1.97 & -0.61 & -0.65 & -0.15 \\
\hline Livestock sick & $5.39 * *$ & 1.72 & -0.13 & $28.13 * * *$ & $12.38 * * *$ & $5.73 * * *$ \\
\hline Death of livestock & $10.87 * *$ & $14.32 * *$ & $13.42 * *$ & $1.44 * * *$ & $4.69 * * *$ & $17.21 * * *$ \\
\hline Death of duck/hen & 0.85 & -0.09 & 0.00 & 0.30 & 9.86 & 0.59 \\
\hline
\end{tabular}

Note: see Table 1.

In sum, food price rise, expanded coverage of other safety net schemes (such as EGPP, VGD and VGF), the introduction of targeted micro-finance schemes and inter-sectoral change altogether may explain why we find a decline in TUP phase 1 program impact towards the second half of 2000-2010. Phase 1 data is not rich enough to examine these issues in detail (BRAC 2009). Nonetheless, we carried out additional tests to verify some of these possibilities. First, external shocks may have eroded the asset base of the program beneficiaries leading to a reduction in the long-run program impact. Table 5 confirms that the longterm estimate of the impact on death of livestock is larger compared to short- and medium-term estimates. More importantly, DD and DD-PSM estimates of the probability of spending money to cover losses owing

\footnotetext{
${ }^{11}$ Although initially introduced in Lalmonirhat, PRIME later covered Rangpur, Nilphamari, Gaibandha and Kurigram.
} 
to livestock shocks are also significant and increases in size over time. ${ }^{12}$ Second, the effect of food crisis of 2009-2012 may help to explain the observed 'long-term' impact on expenditures and food deficit variables in our data. Following the 2007-2008 food price shock, the rural extremely poor saw a $22 \%$ declined in consumption (World Bank 2013). Whilst food price is found to be a significant predictor of food security in TUP phase 1 data, it does not affect the observed program effect (Hossain et al 2015). A third explanation for the decline in program impact relates to the introduction of competing safety net schemes. In the baseline both program and control households reported to be significantly dependent on relief schemes to meet the expenses. Whilst this decreased significantly between 2002 and 2011 amongst treatment households, a similar fall is also noted in the control sample (from $61 \%$ in 2002 to $12.56 \%$ in 2011 ). This suggests the effect of expansion of other safety net schemes in northwestern districts benefitting control households. Lastly, our data suggests a jump in NGO-run microfinance schemes amongst control households between 2008 and 2011 -- percentage of control households reporting taking NGO loans increased from 28 to 35 (see

Appendix Table 3). This could be owing to interventions like PRIME and may explain why the program impact on microfinance participation is significant but smaller in the long-run.

\section{Conclusion and policy implications}

The evidence presented in this paper yields new insights into long-term effects of the TUP intervention. For most outcomes including working age female members' in self-employment, estimated medium term (20022008) effect is larger than the short-run (2002-2005) impact. Reassuringly the long-term impact is also significant in most cases although the effect size points towards a diminishing return when compared to medium term impact. We conjecture that the temporal change in program impact is partly owing to institutional changes in the north-western region. During 2000-2005, most of the reduction in poverty in Bangladesh was driven by growth in non-farm wage and workers moving from agriculture to non-farm work. On the other hand, increase in wages in the agricultural sector was more important for reducing poverty during 2005-2010Our finding of larger impact of TUP program during 2002-2005 and apparently

\footnotetext{
${ }^{12}$ Krishna, Poghosyan and Das (2012) also document vulnerability to downturns owing to negative events such as illnesses and house damage which has resulted in asset losses among SUP households.
} 
smaller impact during 2005-2011 is therefore consistent with the counteracting sectoral patterns in poverty reduction observed during 2000-2010.

The results of this study identify a number of questions that require further examination. First, changes in contextual setting needs to be better understood. This includes the role of competing safety net schemes and improvement in agricultural labor market conditions. Second, women's perception of what constitutes economic activity and household work as household income rises may change. Women's productive and reproductive works are intertwined so that economically well-off women may not report taking care of live animals as productive work. Third, hidden challenges may remain in successful upgradation of microenterprises by poor women in rural areas. Future research should look into hidden challenges underlying successful of management of microenterprises by poor women as well as study changes in their perception of work and employment. Identifying context-specific demand and supply constraints that bind in the long-run can be crucial for ensuring lasting impact of the program above and beyond the project life-cycle. 


\section{Reference}

Ahmed, A. U., R. V. Hill, L. C. Smith, D. M. Wiesmann, and T. Frankenberger (2007) The World's Most Deprived: Characteristics and Causes of Extreme Poverty and Hunger. Washington, DC: International Food Policy Research Institute.

Ahmed, A. U., Mehnaz Rabbani, Munshi Sulaiman, and Narayan C. Das (2009), "The Impact of Asset Transfer on Livelihoods of the Ultra Poor in Bangladesh", Research Monograph Series No. 39, Research and Evaluation Division, BRAC, Dhaka.

Banerjee, A. and Duflo, E. (2011) Poor Economics: A Radical Rethinking of the Way to Fight Global Poverty. Public Affairs: New York City, New York.

Banerjee, Abhijit, Esther Duflo, Raghabendra Chattopadhyay and Jeremy Shapiro (2011) "Targeting the Hard-Core Poor: An Impact Assessment” (mimeo).

Banerjee, A., Duflo, E., Goldberg, N., Karlan, D., Osei, R., Pariente, W., Shapiro, J., Thuysbaret, B. and Urdy, C., (2015) "A multifaceted program causes lasting progress for the very poor: Evidence from six countries”. Science, 348, 1260799. DOI: 10.1126/science.1260799.

BRAC (2009) "Pathways Out of Extreme Poverty: Findings from Round-I Survey of CFPR Phase-II", Research and Evaluation Division, BRAC.

Bandiera, Oriana, Burgess, Robin, Das, Narayan, Gulesci, Selim, Rasul, Imran and Sulaiman, Munshi (2013) "Can Basic Entrepreneurship Transform the Economic Lives of the Poor?," IZA Discussion Papers 7386, Institute for the Study of Labor (IZA).

Das, N. and Shams, R., (2011) “Asset Transfer Program for the Ultra Poor: A Randomized Control Trial Evaluation”, CFPR working paper no 22.

Davis, Peter (2011) "The trappings of poverty: the role of assets and liabilities in socio-economic mobility in rural Bangladesh”, CPRC Working Paper no. 195.

Emran, M., Robano, Virginia and Smith, Stephen (2014) "Assessing the Frontiers of Ultrapoverty Reduction: Evidence from Challenging the Frontiers of Poverty Reduction/Targeting the Ultra-poor, an Innovative Program in Bangladesh," Economic Development and Cultural Change, 62(2), 339 - 380.

Goetz, S., M., and Gupta, R. (1996) "Who Takes the Credit? Gender, Power, and Control Over Loan Use in Rural Credit Programs in Bangladesh”, World Development, Vol. 24, No. 1, pp. 45-63.

Halder, S. and Mosley, P. (2004) "Working with the ultra-poor: Learning from BRAC experience", Journal of International Development, 16, 387-406.

Hashemi, Syed, Schuler, Sidney and Riley, Ann (1996) "Rural credit programs and women's empowerment in Bangladesh", World Development. 24(4):635-53.

Hashemi, Syed (2001) "Linking Microfinance and Safety Net Programs to Include the Poorest: the Case of IGVGD in Bangladesh", Focus Note No. 21 (May), The Consultative Group to Assist the Poorest, Washington D.C. 
Hashemi, Syed and Montesquiou, Aude de (2011) "Reaching the Poorest: Lessons from the Graduation Model", CEGAP Focus Note No 69, 15 March.

Hossain, M., Asadullah, M., Ara, J., Hossain, Amzad (2015) "Rising Food Prices and Household Food Security: Re-assessing the Impact of an Anti-poverty Program" (mimeo).

Jacoby, Hannan and Dasgupta, Basab (2012) "Household exposure to food price increase in rural Bangladesh.” Washington DC: World Bank.

Kabeer, N. 2001. "Conflicts over Credit: Re-Evaluating the Empowerment Potential of Loans to Women in Rural Bangladesh,” World Development, 29: 63-84.

Khandker, S. and Samad (2012) “Is Monga persistent in northwest Bangladesh?” World Bank working paper.

Khandker, S. and Mahmud, Wahiduddin (2011) "Mitigating Seasonal Hunger: Evidence from Northwest Bangladesh," Working Papers id:4631, eSocialSciences.

Khandker, S., Khalily, Baqui, and Samad, Hussain A. (2010) "Seasonal and extreme poverty in Bangladesh : evaluating an ultra-poor microfinance project," Policy Research Working Paper Series 5331, The World Bank.

Khandker, S., Khaleque, M. Abdul and Samad, Hussain A. (2011) "Can social safety nets alleviate seasonal deprivation ? evidence from northwest Bangladesh," Policy Research Working Paper Series 5865, The World Bank.

Krishna, Anirudh, Meri Poghosyan and Narayan Das (2012) "How much can asset transfers help the poorest? The five Cs of community-level development and BRAC's Ultra-Poor Program" Journal of Development Studies, Vol 48(2), pages 254-267.

King, Elizabeth and Jere Behrman (2009) "Timing and Duration of Exposure in Evaluations of Social Programs," World Bank Research Observer, vol. 24(1), pages 55-82.

Quisumbing, Agnes, Bob Baulch and Neha Kumar (2011) "Evaluating the long-term impact of anti-poverty interventions in Bangladesh: an overview," The Journal of Development Effectiveness, vol. 3(2), pages 153174.

Mahmud, S. (2003) “Actually how Empowering is Microcredit?" Development and Change, vol. 34(4): $577-605$.

Matin, Imran, and David Hulme (2003), Programs for the Poorest: Learning from the IGVGD Program in Bangladesh, World Development, 31 (3), 647-665.

Bauchet, J., Morduch, J., and Ravi, S. (2015) "Failure vs. displacement: Why an innovative anti-poverty program showed no net impact in South India” Journal of Development Economics, 116: 1-16.

Sengupta, R., and Aubuchon C., P (2008), “The Microfinance Revolution: An Overview”, Federal Reserve Bank of St. Louis Review, January/February 2008, 90(1), pp. 9-30. 
Shams, R., Mahmud, S., and Das, C. N. (2010). Integration of the Ultra Poor into Mainstream Development: How Effective is CFPR?. CFPR working paper no 21.

World Bank (2013) Bangladesh Poverty Assessment: Assessing a decade of progress in reducing poverty, 2000-2010. 
Appendix Table 1: Baseline comparison between attrition and non-attrition households (2002-2011)

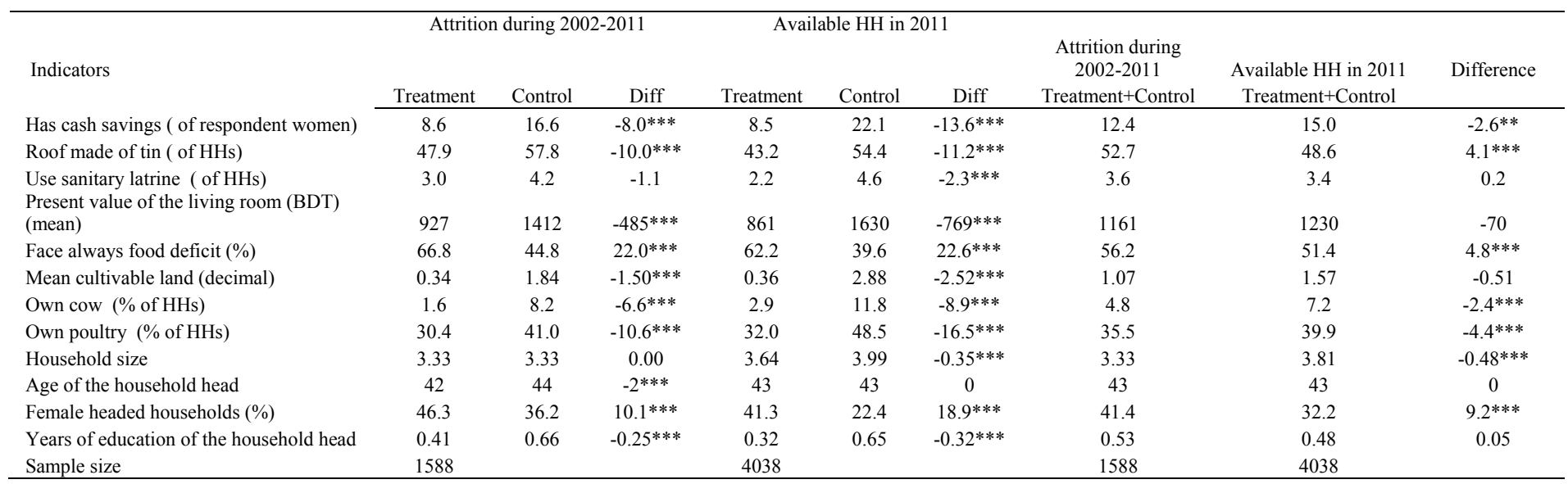

Note: ${ }^{* * *},{ }^{* *}$ and $*$ refer to $1 \%, 5 \%$ and $10 \%$ level of significance respectively.

Appendix Table 2: Probit regression of treatment assignment as a determinant of sample attrition (Dependent variable $=1$ if non-attrition; 0 if attrition)

\begin{tabular}{lrr}
\hline & \multicolumn{1}{c}{$(1)$} & \multicolumn{1}{c}{$(2)$} \\
\hline Treatment household (1 if treatment; 0 if control) & 0.0005 & .00083 \\
& $(0.96)$ & $(0.94)$ \\
Village dummies & No & Yes \\
Number of observations & 5629 & 5629 \\
Adjusted R-squared & 0.0832 & 0.00 \\
\hline
\end{tabular}

Note: p-value in parenthesis. 
Appendix Table 3: Mean differences in key outcome variables by year and program membership status

\begin{tabular}{|c|c|c|c|c|c|c|c|c|c|c|c|c|}
\hline \multirow[t]{2}{*}{ Natural and physical asset } & \multicolumn{3}{|l|}{2002} & \multicolumn{3}{|l|}{2005} & \multicolumn{3}{|l|}{2008} & \multicolumn{3}{|l|}{2011} \\
\hline & $\mathrm{T}_{2002}$ & $\mathrm{C}_{2002}$ & Diff & $T_{2005}$ & $\mathrm{C}_{2005}$ & Diff & $\mathrm{T}_{008}$ & $\mathrm{C}_{2008}$ & Diff & $T_{2011}$ & $\mathrm{C}_{2011}$ & Diff \\
\hline Homestead land owned (decimal) & 1.96 & 3.50 & $-1.55^{* * *}$ & 2.35 & 3.21 & $-0.86^{* * *}$ & 3.25 & 3.84 & $-0.58^{* * *}$ & 2.78 & 3.63 & $-0.85^{* * *}$ \\
\hline Cultivable land owned (decimal) & 0.39 & 2.86 & $-2.47^{* * *}$ & 0.80 & 2.67 & $-1.87^{* * *}$ & 1.33 & 2.71 & $-1.38^{* * *}$ & 0.59 & 2.48 & $-1.89 * * *$ \\
\hline No. of cow/bull owned & 0.05 & 0.20 & $-0.16^{* * *}$ & 1.67 & 0.24 & $1.43 * * *$ & 1.37 & 0.42 & $0.95^{* * *}$ & 0.78 & 0.33 & $0.45^{* * *}$ \\
\hline No. of goat/sheep owned & 0.11 & 0.14 & $-0.04 * *$ & 0.52 & 0.16 & $0.36 * * *$ & 0.62 & 0.28 & $0.34 * * *$ & 0.34 & 0.18 & $0.16^{* * *}$ \\
\hline No. of duck/hen owned & 0.88 & 1.50 & $-0.62^{* * *}$ & 2.60 & 2.67 & -0.07 & 3.86 & 2.52 & $1.34^{* * *}$ & 2.05 & 1.47 & $0.57^{* * *}$ \\
\hline No. of rickshaw/van owned & 0.02 & 0.04 & $-0.03 * * *$ & 0.08 & 0.06 & $0.02 * *$ & 0.10 & 0.07 & $0.03 * * *$ & 0.00 & 0.00 & $0.00^{*}$ \\
\hline No. of Trees owned & 0.59 & 1.36 & $-0.77^{* * * *}$ & 0.75 & 0.87 & -0.12 & 3.83 & 3.98 & -0.15 & 0.01 & 0.01 & $-0.01 * * *$ \\
\hline No. of bed owned & 0.76 & 1.03 & $-0.26^{* * *}$ & 1.10 & 1.23 & $-0.14^{* * * *}$ & 1.35 & 1.41 & $-0.06^{* *}$ & 1.40 & 1.44 & -0.04 \\
\hline No. of chair/table owned & 0.22 & 0.54 & $-0.32^{* * *}$ & 0.56 & 0.81 & $-0.25 * * *$ & 0.89 & 1.07 & $-0.18^{* * *}$ & 1.08 & 1.36 & $-0.28^{* * *}$ \\
\hline \multicolumn{13}{|l|}{ Effect of Treatment on Food Security } \\
\hline Always deficit & 60.10 & 41.91 & $18.20^{* * *}$ & 15.30 & 28.87 & $-13.57^{* * *}$ & 21.02 & 28.45 & $-7.43^{* * *}$ & 42.90 & 44.38 & -1.48 \\
\hline somewhat deficit & 37.27 & 49.23 & $-11.95 * * *$ & 53.67 & 53.51 & 0.17 & 57.20 & 57.22 & -0.02 & 48.81 & 48.92 & -0.11 \\
\hline Neither deficit nor surplus & 2.57 & 7.53 & $-4.95^{* * *}$ & 24.59 & 14.59 & $10.01 * * *$ & 18.64 & 13.09 & $5.54 * * *$ & 7.77 & 5.57 & $2.20^{* * *}$ \\
\hline Surplus & 0.05 & 1.34 & $-1.29 * * *$ & 6.43 & 3.04 & $3.39 * * *$ & 3.15 & 1.24 & $1.91^{* * *}$ & 0.52 & 1.13 & $-0.61 * *$ \\
\hline \multicolumn{13}{|l|}{ Per capita food expenditure and income } \\
\hline Per capita food expenditure (per day) & 60.10 & 41.91 & $18.20^{* * *}$ & 15.30 & 28.87 & $-13.57^{* * *}$ & 21.02 & 28.45 & $-7.43^{* * *}$ & 42.90 & 44.38 & -1.48 \\
\hline Per capita income (yearly) & 37.27 & 49.23 & $-11.95 * * *$ & 53.67 & 53.51 & 0.17 & 57.20 & 57.22 & -0.02 & 48.81 & 48.92 & -0.11 \\
\hline \multicolumn{13}{|c|}{$\begin{array}{l}\text { primary occupation of the working aged individuals (15-60 years) - } \\
\text { MALE }\end{array}$} \\
\hline Farm self-employment & 3.1 & 3.7 & -0.6 & 4.1 & 3.0 & $1.1 *$ & 4.5 & 3.7 & 0.7 & 5.7 & 6.4 & -0.7 \\
\hline Day labour & 66.7 & 59.6 & $7.1 * * *$ & 53.6 & 55.4 & -1.7 & 48.7 & 50.8 & -2.0 & 52.7 & 52.3 & 0.4 \\
\hline Non-farm salaried & 3.2 & 4.2 & -1.0 & 1.9 & 2.2 & -0.4 & 1.9 & 3.0 & $-1.1 * *$ & 4.6 & 5.6 & -1.0 \\
\hline Non-farm self-employment & 16.1 & 22.8 & $-6.7 * * *$ & 20.6 & 21.7 & -1.2 & 19.0 & 19.8 & -0.7 & 19.8 & 23.5 & $-3.7 * * *$ \\
\hline Begging & 1.6 & 0.8 & $0.7 * *$ & 0.8 & 0.6 & 0.2 & 0.7 & 0.5 & 0.3 & 0.9 & 0.4 & $0.6^{* *}$ \\
\hline Servant & 2.1 & 1.4 & 0.7 & 0.5 & 0.1 & $0.4^{* * *}$ & 0.6 & 0.1 & $0.5^{* *}$ & 0.1 & 0.1 & 0.1 \\
\hline Unemployed & 1.5 & 2.5 & $-1.0^{* *}$ & 0.6 & 0.5 & 0.1 & 0.4 & 0.3 & 0.2 & 0.2 & 0.2 & 0.0 \\
\hline \multicolumn{13}{|c|}{$\begin{array}{l}\text { primary occupation of the working aged individuals ( } 15-60 \text { years) - } \\
\text { FEMALE }\end{array}$} \\
\hline Farm-self employment & 0.2 & 0.3 & -0.1 & 42.9 & 8.2 & $34.6 * * *$ & 37.6 & 12.1 & $25.5^{* * *}$ & 39.2 & 36.7 & $2.6^{*}$ \\
\hline $\begin{array}{l}\text { Day labour } \\
\text { Davitit }\end{array}$ & 24.2 & 13.3 & $11.0^{* * *}$ & 14.9 & 16.2 & -1.2 & 12.7 & 15.9 & $-3.2 * * *$ & 7.5 & 5.9 & $1.6^{* *}$ \\
\hline Non-farm salaried & 1.0 & 0.8 & 0.1 & 0.9 & 0.7 & 0.2 & 0.9 & 0.6 & 0.3 & 0.9 & 0.9 & 0.0 \\
\hline Non-farm self-employment & 4.4 & 3.2 & $1.2^{* *}$ & 6.5 & 3.6 & $2.9 * * *$ & 3.4 & 2.9 & 0.4 & 1.7 & 1.1 & $0.6^{*}$ \\
\hline Begging & 3.3 & 1.2 & $2.1 * * *$ & 1.7 & 1.2 & 0.5 & 2.1 & 1.4 & $0.7^{*}$ & 2.3 & 1.3 & $1.0^{* * *}$ \\
\hline Servant & 13.6 & 8.0 & $5.5^{* * *}$ & 6.7 & 8.6 & $-1.9^{* *}$ & 8.4 & 10.4 & $-1.9^{* *}$ & 7.0 & 6.7 & 0.3 \\
\hline Unemployed & 2.9 & 2.9 & 0.0 & 1.7 & 1.6 & 0.0 & 1.4 & 1.9 & -0.5 & 1.7 & 2.2 & -0.5 \\
\hline HH chores & 48.7 & 67.6 & $-18.8^{* * *}$ & 16.1 & 48.9 & $-32.8^{* * *}$ & 22.1 & 41.7 & $-19.6^{* * *}$ & 35.1 & 40.5 & $-5.4^{* * * *}$ \\
\hline \multicolumn{13}{|l|}{ Financial market participation } \\
\hline Have cash savings ( of respondents) & 9.10 & 21.39 & $-12.29 * * *$ & 90.99 & 30.36 & $60.63 * * *$ & 93.76 & 35.93 & $57.83 * * *$ & 98.28 & 47.73 & $50.55^{* * *}$ \\
\hline Have outstanding loans (of HHs) & 26.22 & 39.54 & $-13.32^{* * *}$ & 72.35 & 62.68 & $9.67 * * *$ & 53.77 & 43.66 & $10.11 * * *$ & 35.03 & 34.33 & 0.70 \\
\hline Amount of outstanding loans (Tk.) & 1044 & 2239 & $-1195 * * *$ & 1581 & 1603 & -22 & 2244 & 2780 & $-536^{* * * *}$ & 6019 & 6446 & $-428^{* * *}$ \\
\hline Size of outstanding lending & 1431 & 3672 & $-2241^{*}$ & 2116 & 2588 & -472 & 7908 & 7823 & 85 & 18992 & 15907 & $3084^{* * *}$ \\
\hline Taken loan from NGO & 3.72 & 25.34 & $-21.62^{* * * *}$ & 36.91 & 15.72 & $21.19^{* * *}$ & 52.29 & 28.69 & $23.60^{* * *}$ & 51.38 & 35.30 & $16.07 * * *$ \\
\hline Taken loan from informal sources & 95.96 & 72.07 & $23.89^{* * *}$ & 62.90 & 83.99 & $70.14 * * *$ & 47.36 & 70.14 & $-22.78^{* * *}$ & 48.17 & 64.07 & $-15.91 * * *$ \\
\hline \multicolumn{13}{|c|}{$\begin{array}{l}\text { Type of crisis ( of households) Crisis/Incidence occurred in last one } \\
\text { year (yes }=1 \text { ) }\end{array}$} \\
\hline House damaged & 41.60 & 37.70 & $3.90^{* *}$ & 18.27 & 12.43 & $5.84 * * *$ & 8.64 & 7.01 & $1.62 * *$ & 24.49 & 23.17 & 1.16 \\
\hline HH members seriously ill & 23.38 & 24.24 & -0.86 & 15.89 & 17.17 & $\begin{array}{l}.07 \\
-1.29\end{array}$ & 12.93 & 12.53 & -0.40 & 22.16 & 22.37 & -0.52 \\
\hline Death of livestock & 3.29 & 4.59 & $-1.30^{* * *}$ & 8.73 & 2.78 & $5.95^{* * *}$ & 6.58 & 3.09 & $3.49 * * *$ & 21.45 & 6.63 & $14.70^{* * *}$ \\
\hline
\end{tabular}




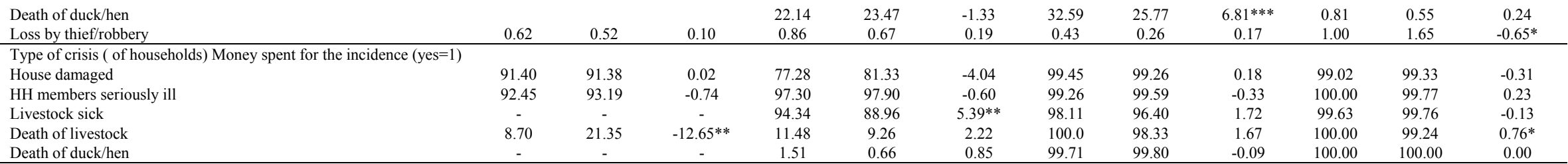

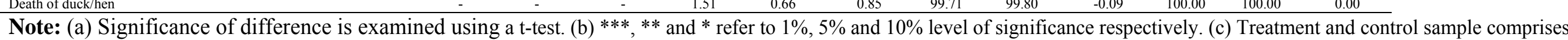
of 2098 and 1,940 households respectively. 
Appendix Table 4: Probit regression of determinants of TUP program participation using full sample (dependent variable 1 if treatment household; 0 otherwise)

\begin{tabular}{|c|c|c|c|}
\hline & Coefficient & z value & $P$ value \\
\hline Female headed household $(\mathrm{Yes}=1 ; \mathrm{No}=0)$ & 0.345 & 6.00 & 0.001 \\
\hline Household size & 0.097 & 5.72 & 0.003 \\
\hline Amount of own land (decimal) & -0.019 & -6.60 & 0.001 \\
\hline Received Govt. benefit $(\mathrm{Yes}=1 ; \mathrm{No}=0)$ & -0.528 & -2.85 & 0.004 \\
\hline Have outstanding loan $(\mathrm{Yes}=1 ; \mathrm{No}=0)$ & -0.280 & -6.12 & 0.00 \\
\hline Main occupation of the main female member of the household is housemaid or begging $(\mathrm{Yes}=1 ; \mathrm{No}=0)$ & -0.102 & -1.02 & 0.309 \\
\hline No. of active female member & 0.150 & 3.02 & 0.003 \\
\hline No. of active male member & -0.256 & -5.54 & 0.003 \\
\hline owned cow/bull $(\mathrm{Yes}=1 ; \mathrm{No}=0)$ & -0.545 & -6.11 & 0.001 \\
\hline owned goat/sheep $(\mathrm{Yes}=1 ; \mathrm{No}=0)$ & -0.040 & -0.50 & 0.618 \\
\hline owned hen/duck $(\mathrm{Yes}=1 ; \mathrm{No}=0)$ & -0.185 & -4.20 & 0.00 \\
\hline owned rickshaw/van $(\mathrm{Yes}=1 ; \mathrm{No}=0)$ & -0.484 & -3.35 & 0.001 \\
\hline owned radio $(\mathrm{Yes}=1 ; \mathrm{No}=0)$ & -0.301 & -1.62 & 0.106 \\
\hline Owned ornaments $(\mathrm{Yes}=1 ; \mathrm{No}=0)$ & -0.061 & -0.27 & 0.786 \\
\hline Owned shop $(\mathrm{Yes}=1 ; \mathrm{No}=0)$ & -0.521 & -0.97 & 0.333 \\
\hline Main house roof made of straw $(\mathrm{Yes}=1 ; \mathrm{No}=0)$ & 0.194 & 4.53 & 0.001 \\
\hline Average schooling of the household members (years) & -0.038 & -7.45 & 0.002 \\
\hline Faced any incidence /crisis $(\mathrm{Yes}=1 ; \mathrm{No}=0)$ & -0.084 & -1.99 & 0.047 \\
\hline Improved economic status in last one year & 0.217 & 3.37 & 0.001 \\
\hline Constant & -0.019 & -0.23 & 0.815 \\
\hline No. of observations & 4038 & & \\
\hline Pseudo R-square & 0.09 & & \\
\hline
\end{tabular}

